\title{
An Assay in Microtitre Plates for Absolute Abundance of Chicken Interferon Alpha Transcripts
}

\author{
Renata Novak Kujundžić ${ }^{1}$, William Lauman Ragland² \\ ${ }^{1}$ Division of Molecular Medicine, Institut Ruđer Bošković, Zagreb, Croatia \\ ${ }^{2}$ Zagreb Biotek d.o.o., Supetar, Croatia \\ Received June 29, 2009 \\ Accepted May 13, 2010
}

\begin{abstract}
Immunosuppression of commercial chickens is a serious animal health and economic problem in the poultry industry. The major causes of the immunosuppression are viruses that suppress transcription of interferon genes, especially interferon alpha. There is a need for monitoring immunosuppression in commercially bred chickens. For this purpose, the absolute abundance of interferon alpha transcripts can be measured in blood of chickens by a suitable assay. Such an assay was used to estimate abundance of chicken interferon alpha in a sample of splenic cells induced with polyinosinic polycytidylic acid. The abundance measured was $29 \pm 2$ attomoles/ $\mu g$ total RNA. This assay can be performed in microtitre plates using samples collected from chickens in poultry houses.
\end{abstract}

$m R N A$, absolute abundance, poly I:C

Although various agents can cause immunosuppression in commercial chickens, infectious diseases especially caused by viruses are the most frequent and serious causes. There are three such viruses recognized as being economically important; Marek's disease virus, chicken anaemia virus and infectious bursal disease virus. Most viruses cause some immunosuppression and possibly all viruses do, even attenuated vaccines (Strasser et al. 2003), but health of infected animals and economic impact of immunosuppression by these viruses is usually trivial.

Many bacteria are immunosuppressive in various hosts (Schwab 1975), including the chicken (Hassan and Curtiss 1994; Kishida et al. 2004). It has been known since the early 1970s that mycoplasmas are immunosuppressive in several species (Kaklamanis and Pavlatos 1972), chickens among them (Nonomura 1973; Ganapathy and Bradbury 2003). Mycotoxins are immunosuppressive but their effects can be prevented by quality control of feedstock to avoid feeding contaminated feed (Devegowda and Murthy 2005).

It has been known since at least the early 1990s that viruses have assorted strategies for suppressing interferon (IFN) production by an infected host (Goodbourn et al. 2000) and they continue to be actively investigated (Garcia-Sastre and Biron 2006). We hypothesised that the important immunosuppressive viruses of chickens would suppress IFN gene transcription. If true, failure to induce IFN gene activation with an inducer would identify most immunosuppressed chickens, and induction of increased abundance would strongly imply that a flock was immunologically competent.

As there was no fast, facile and inexpensive method to assess immune status of chickens (Bacon 1992), we developed molecular hybridization assays in microtitre plates to assess the abundance of both chicken interferon alpha (ChIFN- $\alpha$ ) and interferon gamma $(\mathrm{ChIFN}-\gamma)$ transcripts in chicken blood before and several hours after challenge with an inducer of IFN (Novak et al. 2001). These tests were used to confirm that Marek's disease virus (Quéré et al. 2005), chicken anaemia virus and infectious bursal disease virus suppress gene transcription of both ChIFN- $\alpha$ and ChIFN- $\gamma$ (Ragland et al. 2002).

Address for correspondence:

Dr. William L. Ragland

Zagreb Biotek d.o.o.

Frane Petrinovića 1

21400 Supetar,, CROATIA

Phone: +38521091187043
Fax: +38521630295
E-mail: zagreb.biotek@email.t-com.hr
http://www.vfu.cz/acta-vet/actavet.htm 
Virulent Marek's disease virus suppressed induction of IFN gene transcription, while the vaccinal turkey herpesvirus did not. The assay lasted two days and it measured just relative and not absolute abundance. These deficiencies led us to improve the assay. We focused on ChIFN- $\alpha$ because of its importance in an early response to infection and because of stronger suppression by the viruses than in case of ChIFN- $\gamma$ (Ragland et al. 2002).

\section{Materials and Methods}

\section{Probes}

Biotin-labelled oligo(dT) ${ }_{20}$ probe (Roche, Penzberg, Germany) was used for capturing samples or standards to streptavidin-coated microtitre plates. Three digoxygenin-labelled $\mathrm{ChIFN}-\alpha$-specific probes were produced by PCR using Roche's Digoxygenin labelled probe synthesis kit according to the manufacturer's instructions. Plasmid DNA extracted from Escherichia coli strain DH5 $\alpha$ transformed with SPORT1 plasmid containing ChIFN- $\alpha$ DNA, kindly provided by Drs. Sekellick and Marcus (Sekellick et al. 1994), was used as a template. Primers used for the amplification of ChIFN- $\alpha$ probe were forward 5'-ATGGCTGTGCCTGCAAGCCCA-3' and reverse 5'-CTAAGTGCGCGTGTTGCCTGT-3'. The PCR reaction proceeded for 30 cycles with annealing temperature of $60^{\circ} \mathrm{C}$. Product of PCR was analysed by electrophoresis on agarose mini gel stained with ethidium bromide. A difference in migration of digoxygenin-labelled PCR products and unlabelled PCR products was an indicator of incorporation of digoxygenin in the probe.

\section{Assay design}

A standard curve was constructed each time an assay was performed (nine for each probe) by using serial dilutions of a defined amount $(8,000$ to $0 \mathrm{amol} / \mathrm{ml})$ of the synthetic oligonucleotide containing polyA tail for ChIFN- $\alpha$ (5'-TGTAATCGTTGTCTTGGAGGAAAAAAAA-3) (Invitrogen, Carlsbad, CA) in hybridization buffer $(0.75 \mathrm{M}$ sodium chloride; 0.75 sodium citrate; $3 \mu \mathrm{l} / \mathrm{ml}$ Tween-20, $1 \%$ BSA). Serial dilutions of total RNA $(40-0 \mu \mathrm{g} / \mathrm{ml})$ extracted from splenocytes treated with polyinosinic:polycytidylic acid (poly I:C) were prepared in the same buffer. An uncoated, hybridization plate was washed with washing buffer $(0.01 \mathrm{M}$ Tris- $\mathrm{HCl}, \mathrm{pH} 7.5$; $0.2 \mathrm{M} \mathrm{LiCl} ; 1 \mathrm{mM}$ EDTA, pH 8.0; $200 \mu \mathrm{l}$ /well), buffer was removed by aspiration and $150 \mu \mathrm{l}$ of each dilution of standard or sample was placed in each of three wells. Digoxygenin-labelled ChIFN- $\alpha$-specific probe $(4 \mu \mathrm{l}$ of PCR product as per manufacturer's instructions) was denatured by boiling for $10 \mathrm{~min}$ and mixed with biotin-labelled oligo $(\mathrm{dT})_{20}$ probe $(0.1 \mathrm{nmol})$ per millilitre of hybridization buffer. This probe mix was added $(50 \mu \mathrm{l} /$ well $)$, the plate sealed with adhesive foil and hybridization proceeded for $60 \mathrm{~min}$ at $65^{\circ} \mathrm{C}$. A streptavidin-coated microtitre plate (Sigma-Aldrich Chemie GmbH, Steinheim, Germany) was washed twice with $200 \mu$ of washing buffer, the buffer removed and $150 \mu \mathrm{l}$ of the contents of each well from the hybridization plate was, upon completion of the hybridization period, transferred to wells of the streptavidin-coated plate. The plate was sealed with adhesive foil and incubated at ambient temperature to allow binding of biotin to streptavidin. To remove the unbound hybridization mix, the plate was washed $4 \times$ with $200 \mu$ of washing buffer per well. Anti-digoxygenin AP conjugate (Roche) was diluted 1:2,000 in antibody dilution buffer $(0.1 \mathrm{M}$ Tris-HCl, $\mathrm{pH} 7.5 ; 0.15 \mathrm{M} \mathrm{NaCl})$ and $100 \mu \mathrm{l}$ was placed into each well. The plate was incubated for $60 \mathrm{~min}$ at ambient temperature, followed by washing $5 \times$ with washing buffer, and then one wash with alkaline phosphatase buffer (1M diethanolamine, $0.5 \mathrm{mM} \mathrm{MgCl}, \mathrm{pH} 9.8$ ). An alkaline phosphatase substrate, p-nitrophenyl phosphate (Sigma), was dissolved in alkaline phosphatase buffer and $100 \mu$ ladded to each well. The plate was incubated at ambient temperature in the dark for $30 \mathrm{~min}$ and the absorbance was measured immediately at $405 \mathrm{~nm}$ with a microtitre plate reader.

Induced sample

To prepare a primary spleen cell culture, one-week-old specific pathogen-free (SPF) chickens were killed by cervical dislocation and their spleens were aseptically removed and placed in physiological PBS. The spleens were forced through a 60-mesh screen of a TissueCell Dissociation Kit (Sigma). The cell suspension was collected and centrifuged for $10 \mathrm{~min}$ at $350 \times \mathrm{g}$ and the pellet was suspended in physiological PBS. The suspension was carefully layered on top of $4 \mathrm{ml}$ of Ficoll-Paque (Pharmacia Biotech, Inc., Piscataway, NJ), centrifuged at $400 \times g$ for $15 \mathrm{~min}$ and the cells at the interface were harvested. After washing in PBS, the cells were suspended and maintained in RPMI 1640 medium supplemented with 2\% chicken serum, 8\% FBS, $100 \mathrm{U} / \mathrm{ml}$ penicillin and $100 \mu \mathrm{g} / \mathrm{ml}$ streptomycin and grown at $40{ }^{\circ} \mathrm{C}$ in a water-saturated $5 \% \mathrm{CO}_{2}$ and $95 \%$ air atmosphere.

These chicken splenocytes were stimulated with poly I:C $(25 \mu \mathrm{g} / \mathrm{ml})$ for $24 \mathrm{~h}$ and their total RNA was isolated using TRI reagent (Sigma) according to the manufacturer's instructions. Integrity of RNA was determined by electrophoresis on a $1 \%$ agarose gel. The concentration of total RNA in the sample was determined spectrophotometrically. Poly I:C is a synthetic double-stranded RNA that binds to TLR 3, stimulating production of IFN- $\alpha$.

\section{Statistical analysis}

Regression analysis of each replicate (in triplicate) for two selected probes (probe 1 and probe 3) was performed with JMP statistical software (SAS Institute Inc., Cary, NC). Tests for normal distribution, equal variance and means comparison were performed with JMP. Slopes and intercepts of combined regression curves 
for the two probes were compared by $t$-tests (Zar 1984). Regression equations were used to calculate abundance of ChIFN-a mRNA in the unknown sample. The Wilcoxon ranked-sums test was used to compare estimates of absolute abundance of transcripts estimated in the unknown sample with the two probes. Values of $p \leq 0.05$ were considered significant.

\section{Results}

All three probes yielded curvilinear plots over the full range of dilution tested (Fig. 1) with an obvious deflection that began between 25 and 50 attomoles. Probes 1 and 3 were linear to 25 attomoles (Fig. 2) but probe 2 was curvilinear (data not shown). Probe 2 could be linearized by $\log \log$ transformation but was not considered any further. The $\mathrm{R}^{2}$ for combined replicates was 0.88 for probe 1 and 0.90 for probe 3 . Regression slopes and intercepts were different for the two probes.

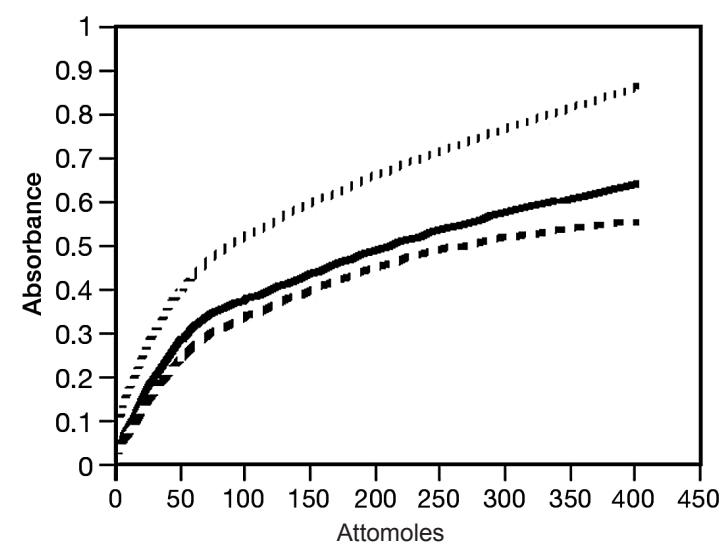

Fig. 1. Correspondence of ChIFN- $\alpha$ oligonucleotide standard hybridized to a capture probe as measured by absorbance signal in microtitre plates (see text for details). Plots are spline best fit, $\mathrm{R}^{2}=0.997$ or higher for all 3 probes $($ solid line $=$ probe 1 , hatched line $=$ probe 2 , dashed line $=$ probe 3$)$.

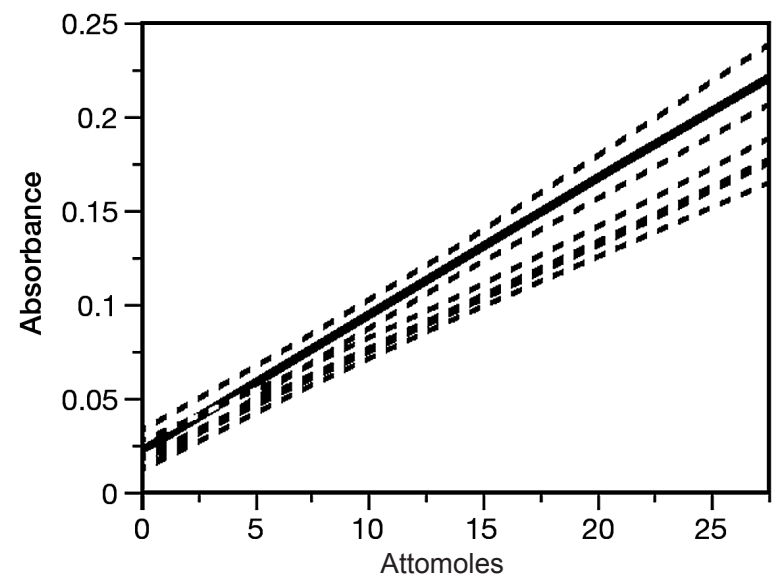

Fig. 2. Linear fit of probe 1 (solid line) and probe 3 (broken line). The accompanying curvilinear plots represent $95 \%$ confidence intervals for each probe. 
Table 1. Regression coefficients and estimates of ChIFN- $\alpha$ mRNA abundance in an unknown sample using two different probes

\begin{tabular}{|c|c|c|c|c|}
\hline \multicolumn{2}{|c|}{ Replicate curves } & \multicolumn{2}{c|}{ Attomoles mRNA } & Attomoles mRNA/ $\mu$ g total RNA \\
\hline Each & $\mathrm{R}^{2}$ & Each replicate & Each probe & Each probe \\
\hline 1.1 & 0.994 & 15.5 & $12.2 \pm 1.6(13)^{*}$ & $30.5 \pm 4.0(13)^{*}$ \\
\hline 1.2 & 0.996 & 13.6 & & \\
\hline 1.3 & 0.929 & 12.5 & & \\
\hline 1.4 & 0.989 & 10.3 & & \\
\hline 1.5 & 0.975 & 12.7 & & \\
\hline 1.6 & 0.994 & 12.0 & & \\
\hline 1.7 & 0.988 & 11.0 & & \\
\hline 1.8 & 0.978 & 10.9 & & \\
\hline 1.9 & 0.979 & 11.7 & & \\
\hline 3.1 & 0.989 & 11.5 & $11.1 \pm 1.0(9)^{*}$ & \\
\hline 3.2 & 0.987 & 9.8 & & \\
\hline 3.3 & 0.976 & 10.3 & & \\
\hline 3.4 & 0.990 & 11.3 & & \\
\hline 3.5 & 0.990 & 10.8 & & \\
\hline 3.6 & 0.985 & 10.2 & & \\
\hline 3.7 & 0.983 & 13.0 & & \\
\hline 3.8 & 0.990 & 11.6 & & \\
\hline 3.9 & 0.990 & 11.8 & & \\
\hline
\end{tabular}

$*$ Mean $\pm \mathrm{SD}(\% \mathrm{CV})$ of nine replicates

The $\mathrm{R}^{2}$ for individual replicate curves for probes 1 and 3 and estimated abundance in the unknown sample are presented in Table 1. Regression equations for each of the solitary curves (in triplicate) were used to estimate abundance of mRNA in the sample. The data were normally distributed and had equal variance. The CV for probe 1 was $13 \%$, and for probe 3 was $9 \%$. The mean abundances for the two probes were not different $(p=0.10)$, thus they both measured the same abundance in the sample.

\section{Discussion}

It is obvious that probes 1 and 3 measured the same absolute abundance in the unknown sample. Precision was better for solitary than for combined assays. Precision still was acceptable for combined assays (CV of $13 \%$ and $9 \%$ ), especially considering that the replicates were performed on different days.

Non-induced cells were not assayed because the abundance of ChIFN- $\alpha$ transcripts is extremely low. Xing and Schat (2000) were unable to detect IFN- $\alpha$ transcripts in spleens of naïve SPF chickens. Abdul-Careem et al. (2008) detected IFN- $\alpha$ transcripts in bursae of Fabricius of one-day-old, naïve SPF chickens but at very low level.

A kit to measure abundance of murine IFN- $\gamma$ transcripts was developed by R\&D Systems (Minneapolis, Minnesota). According to their data, splenocyte cell cultures stimulated with phytohaemagglutinin for $24 \mathrm{~h}$ contained 26 attomoles of interferon per $\mu \mathrm{g}$ total RNA. In our study, we obtained similar abundance of 29 attomoles of ChIFN- $\alpha$ per $\mu \mathrm{g}$ total RNA.

During an epornitic of infectious chicken anaemia in commercially bred broilers in Croatia and Slovenia, we tested the immune status of affected broilers in Croatia using our original assay (Ragland et al. 2002). We noticed that abundance of IFN- $\alpha$ and IFN- $\gamma$ in the birds before challenge with an IFN inducer was less than usually observed in healthy chickens. This prompted us to wonder if immunosuppression caused by immunosuppressive viruses could be identified based on absolute abundance and thus avoid the second sample after 
challenge with an inducer. Comparison with historical controls is imprecise, and moreover, comparison of relative abundance among flocks assayed at different times would be questionable, hence, there is a need to measure absolute abundance to circumvent these problems.

Measurement of absolute abundance of interferon transcripts has not been done frequently until now. Previous measurements were based on biological assays of interferon produced by cells injected with total RNA, and thus abundance was reported as biological units of interferon produced (Stewart 1981). Quantitative RT-PCR has been used as a research tool to measure absolute abundance of ChIFN- $\alpha$ transcripts, as well as other chicken cytokine transcripts (Hong et al. 2006a,b; Eldaghayes et al. 2006; Li et al. 2007; Patel et al. 2008). We have focused on a less expensive method to assess abundance of ChIFN- $\alpha$ transcripts in commercial chickens.

This assay can be used also for other agents that suppress interferon gene transcription. Bacteria Mycobacterium tuberculosis, M. ulcerans and M. avium are immunosuppressive and cause systemic suppression of IFN- $\gamma$ gene expression (Lafuse et al. 2006; YeboahManu et al. 2006). Their effect on IFN- $\alpha$ has not been studied but in instances where viral effects on both interferons have been examined, both usually were suppressed. The question is if the same occurs in bacterial infections. Concerning mycoplasma, we have preliminary evidence that mycoplasma suppresses interferon gene expression in chickens (unpublished observations). The fumonosin mycotoxins have been also reported to suppress ChIFN- $\alpha$ transcription (Cheng et al. 2006).

The described assay is adequate for assessment of immune status of commercially bred chickens by laboratories that cannot use the qRT-PCR and are equipped with standard ELISA readers. It will be useful for identifying and monitoring immunosuppressed flocks.

\section{References}

Abdul-Careem MF, Hunter BD, Lee LF, Fairbrother JH, Haghighi HR, Read L, Parvizi P, Heldari M, Sharif S 2008: Host responses in the bursa of Fabricius of chickens infected with virulent Marek's disease virus. Virology 379: 256-265

Bacon LD 1992: Measurement of immune competence in chickens. Poult Sci Rev 4: 187-195

Cheng YH, Ding ST, Chang MH 2006: Effect of fumonisins on macrophage immune functions and gene expression of cytokines in broilers. Arch Anim Nutr 60: 267-276

Devegowda G, Murthy TNK 2005: Mycotoxins: their effects in poultry and some practical solutions. In: Diaz DE (Ed.): The Mycotoxin Blue Book. Nottingham University Press, Nottingham, pp. 25-56

Eldaghays I, Rothwell L, Williams A, Withers D, Balu S, Davison F, Kaiser P 2006: Infectious bursal disease virus: Strains that differ in virulence differentially modulate the innate immune response to infection in the chicken bursa. Viral Immunol 19: 83-91

Ganapathy K, Bradbury JM 2003: Effects of cyclosporine A on the immune responses and pathogenesis of a virulent strain of Mycoplasma gallisepticum in chickens. Avian Pathol 32: 495-502

Garcia-Sastre A, Biron CA 2006: Type 1 interferons and the virus-host relationship: A lesson in détente. Science 312: $879-882$

Goodbourn S, Didcock L, Randall RE 2000: Interferons; cell signaling, immune modulation, antiviral responses and virus countermeasures. J Gen Virol 81: 2341-2364

Hassan DL, Curtiss R 1994: Virulent Salmonella typhimurium-induced lymphocyte depletion and immunosuppression in chickens. Infect Immun 62: 2027-2036

Hong YH, Lillehoj HS, Lee SH, Dalloul RA, Lillehoj EP 2006a: Analysis of chicken cytokine and chemokine gene expression following Eimeria acervulina and Eimeria tenella infections. Vet Immun Immunopath 114: 209-233

Hong YH, Lillehoj HS, Lillehoj EP, Lee SH 2006b: Changes in immune-related gene expression and intestinal lymphocyte subpopulations following Eimeria maxima infection of chickens. Vet Immun Immuopath 114: 259-272

Kaklamanis E, Pavlatos M 1972: The immunosuppressive effect of mycoplasma infection. I. Effect on the humoral and cellular response. Immunology 22: 695-702

Kishida N, Sakoda Y, Eto M, Sunaga Y, Kida H 2004: Co-infection of Staphylococcus aureus or Haemophilus paragallinarum exacerbates H9N2 influenza A virus infection in chickens. Arch Virol 149: 2095-2104

Lafuse WP, Alvarez GR, Curry HM, Zwilling BS 2006: Mycobacterium tuberculosis and Mycobacterium avium inhibit IFN- $\gamma$-induced gene expression by TLR-dependent and independent pathways. J Interferon Cytokine Res 26: 548-561 
Li YP, Handberg KJ, Juul-Madsen HR, Zhang MF, Jørgensen PH 2007: Transcriptional profiles of chicken embryo cell cultures following infection with infectious bursal disease virus. Arch Virol 152: 463-478

Nonomura I 1973: Interference of Mycoplasma-gallisepticum with multiplication of Newcastle-disease virus in chicken tracheal organ-cultures. Natl I Anim Health Q 13: 105-111

Novak R, Ester K, Savić V, Sekellick MJ, Marcus PI, Lowenthal J, Vainio O, Ragland WL 2001: Immune status assessment by abundance of interferon alpha and gamma mRNA in chicken blood. J Interferon Cytokine Res 21: $643-651$

Patel BA, Gomis S, Dar AD, Wilson PJ, Babiuk LA, Potter A, Mutwir G, Tikoo SK 2008: Oligodeoxynucleotides containing $\mathrm{CpG}$ motifs (CpG-ODN) predominantly induce Th1-type immune response in neonatal chicks. Dev Comp Immunol 32: 1041-1049

Quéré P, Rivas C, Ester K, Novak R, Ragland WL 2005: Abundance of IFN- $\alpha$ and IFN- $\gamma$ mRNA in blood of resistant and susceptible chickens infected with Marek's disease virus (MDV) or vaccinated with turkey herpesvirus; and MDV inhibition of subsequent induction of IFN gene transcription. Arch Virol 150: 507-519

Ragland WL, Novak R, El-Attrache J, Savić V, Ester K 2002: Chicken anemia virus and infectious bursal disease virus interfere with transcription for chicken IFN- $\alpha$ and INF- $\gamma$ mRNA. J Interferon Cytokine Res 22: 437-441

Ragland WL, Savić V, Novak R, Ester K 2002: Abundance of ChIFN- $\alpha$ and ChIFN- $\gamma$ mRNA in blood of broiler chickens during an outbreak of chicken infectious anaemia. FASEB J 16: A304

Schwab JH 1975: Suppression of the immune response by microorganisms. Bacteriol Rev 39: 121-143

Sekellick MJ, Ferrandino AF, Hopkins DA, Marcus PI 1994: Chicken interferon gene: cloning, expression and analysis. J Interferon Res 14: 71-79

Stewart WE 1981: The Interferon System, $2^{\text {nd }}$ edn. Springer-Verlag, Wien, 493 p.

Strasser A, May B, Tettscher A, Wistrela E, Niedermüller H 2003: Immune modulation following immunization with polyvalent vaccines in dogs. Vet Immunol Immunopath 94: 113-121

Xing Z, Schat KA 2000: Expression of cytokine genes in Marek's disease virus-infected chickens and chicken embryo fibroblast cultures. Immunology 100: 70-76

Yeboah-Manu D, Peduzzi E, Mensah-Quainoo E, Asante-Poku, A, Ofori-Adjei D, Pluschke G, Daubenberger CA 2006: Systemic suppression of interferon-gamma responses in Buruli ulcer patients resolves after surgical excision of the lesions caused by the extracellular pathogen Mycobacterium ulcerans. J Leukocyte Biol 79: $1150-1156$

Zar JH 1984: Biostatistical Analysis, $2^{\text {nd }}$ edn. Prentice-Hall, Inc., Englewood Cliffs, pp. 292-305 